\title{
Quantification of the influence of rolling stock failures on track deterioration"
}

\author{
Yun-guang YE ${ }^{1}$, Da-chuan SHI ${ }^{\dagger 1}$, Sara POVEDA-REYES ${ }^{2}$, Markus HECHT ${ }^{1}$ \\ ${ }^{1}$ Institute of Land and Sea Transport Systems, Technical University of Berlin, Berlin 10587, Germany \\ ${ }^{2}$ AITEC, Parque Tecnológico, Valencia 46980, Spain \\ †E-mail: dachuan.shi@tu-berlin.de
}

Received Jan. 21, 2020; Revision accepted Aug. 28, 2020; Crosschecked Sept. 27, 2020

\begin{abstract}
This study focuses on the quantification of the influence of rolling stock failures (RSFs) on railway infrastructure. Taking the wheel flat, a common RSF, as an example, we introduce four quantification indexes to evaluate the influence on the following four deterioration mechanisms: track settlement (TS), track component fatigue (TCF), abrasive wear (AW), and rolling contact fatigue (RCF). Our results indicate that TS, TCF, and AW increase sharply with the increase of the wheel flat length and the vehicle speed, and this increasing trend becomes more acute with the increase of the wheel flat length and the vehicle speed. At low speeds, RCF increases gradually as the wheel flat length increases; at high speeds, it increases sharply at first and then decreases gradually. The influence of the wheel flat on TCF and AW is the most obvious, followed by TS and RCF. These findings can help infrastructure managers (IMs) to better understand infrastructure conditions related to RSFs and can aid them in managing problems with vehicle abnormality in track access charging.
\end{abstract}

Key words: Rolling stock failure (RSF); Track deterioration; Quantification; Track charging; Wheel flat https://doi.org/10.1631/jzus.A2000033

CLC number: U270

\section{Introduction}

\subsection{Quantification of track deterioration}

Deterioration of rail tracks is an inevitable phenomenon of the railway infrastructure affected by traffic and climate and is one of the main concerns for train operators and throughout infrastructure sectors (Smith et al., 2017). In terms of running safety, even a small geometric deviation may pose a risk of serious disasters. In 2015, the failure of track geometry was

\footnotetext{
‡ Corresponding author

* Project supported by the Assets4Rail Project Funded by the Shift2Rail Joint Undertaking under the EU's H2020 Program (No. 826250) and the China Scholarship Council (No. 201707000113). Open access funding provided by Projekt DEAL

(iD) ORCID: Yun-guang YE, https://orcid.org/0000-0002-2921-8420; Da-chuan SHI, https://orcid.org/0000-0002-9296-7213; Sara POVEDAREYES, https://orcid.org/0000-0002-4869-5134

(C) The Author(s) 2020
}

the second leading cause of freight wagon derailments in the USA (Higgins and Liu, 2018). The deterioration of rail tracks and related vehicle components (e.g. bearings, axles, and wheelsets) and infrastructures (e.g. rails, sleepers, and fasteners) significantly increases the frequency of needed maintenance and decreases the service life of related components (Soleimanmeigouni et al., 2018). In addition, poor conditions of rail tracks increase noise, energy consumption, and running costs (Odolinski and Nilsson, 2017). More detailed quantitative descriptions of the process of track deterioration may aid infrastructure managers (IMs) to improve running safety, maintenance strategies, and track access charging across rail systems.

To date, track deterioration mechanisms are mainly classified into four categories: track settlement (TS), track component fatigue (TCF), abrasive wear (AW), and rolling contact fatigue (RCF), and 
each category has a corresponding quantitative index depending on vehicle characteristics and generated wheel-rail (WR) forces (Öberg and Andersson, 2009). At present, the combination of these indexes has two functions: (1) estimating the marginal cost for railway tracks (track charging model) and (2) evaluating the track friendliness for railway vehicles (track friendliness evaluation model).

\section{(1) Track charging model}

Currently, three strategies are adopted to analyze railway costs, as detailed by Wheat and Smith (2008): engineering simulations and econometric estimation (bottom-up model); econometric estimation of a cost function (top-down model); cost allocation model (top-down model). The bottom-up model, or twostage approach, relies on engineering simulation including (1) engineering simulation methods that estimate the track deterioration caused by vehicles and (2) econometric methods that estimate the relationship between the actual maintenance costs and the different deterioration mechanisms. Wheat and Smith (2008) proposed this model to estimate the marginal cost of different types of vehicles on the rail infrastructure. In the engineering simulation, three deterioration mechanisms (TS, AW, and RCF) were considered. The econometric results indicated that TS is the most expensive of the three mechanisms in terms of the maintenance cost, followed by RCF and AW. Öberg and Andersson (2009) developed a bottom-up track charging model, considering TS, TCF, AW, and RCF in the context of Swedish mainline traffic and vehicles; additional similar studies have also been conducted (Smith et al., 2015, 2016).

(2) Track friendliness evaluation model

This is the first stage of the bottom-up charging model. Bruni et al. (2016) used TS, TCF, AW, and RCF to assess the track friendliness of passive and active steering in railway bogies, in which five concepts of the bogie for a Co-Co locomotive were investigated: passive steering using mechanical linkages (EMD), passive hydraulic steering (PHS), active steering using secondary yaw control (SYC), active hydraulic steering (AHS), and self-steering secondary yaw control (SS-SYC). The survey showed that the EMD, AHS, and SS-SYC concepts could significantly reduce RCF and AW, and the SS-SYC and EMD concepts could significantly reduce TS and TCF.
In these studies, researchers considered characteristics such as vehicle type, bogie structure, and curve radius as variables, studying changes in quantification indexes (TS, TCF, AW, and RCF), which are used to evaluate track deterioration. However, the abnormal interaction between rolling stock and infrastructure, which could be caused by RSFs such as wheel flats, brake failure, and suspension faults, was not considered. More information concerning the influence of WR interface on track deterioration can be found in (Smith, 2003; Falomi et al., 2011; Halama et al., 2011; Liang et al., 2013; Ye et al., 2020a).

\subsection{Rolling stock failures (RSFs)}

RSFs, including carbody failures (CBFs) and rolling gear failures (RGFs), have a great impact on running safety and may increase the risk of derailment. According to a report of the D-RAIL project (Andreas et al., 2012), between 2005-2010 derailment accidents caused by RSFs accounted for the highest proportion of accidents (38\%) followed by infrastructure failures (34\%), in 14 European countries (Austria, France, Germany, the UK, Sweden, Switzerland, Belgium, Bulgaria, Czech Republic, Hungary, Italy, the Netherlands, Poland, Slovenia), as shown in Fig. 1a. In fact, RSFs directly affect the infrastructure and may accelerate track deterioration, thereby increasing the probability of infrastructure failures.

Among RSFs, rolling gear failure (RGF) usually has the greatest impact on track deterioration due to more severe WR interactions. In our previous work (Hecht et al., 2018), we conducted a statistical analysis on the RSFs of three European railway companies. The data provided by the three companies indicated that there were approximately 95500 damaged vehicles with a total of approximately 244500 RSFs in a year, including CBFs and RGFs. Specifically, we conducted a separate analysis on the RGFs (Fig. 1b), and the results showed that the four leading failures were wheel flat, axlebox failure, material deposition, and thermal overload, with wheel flat failure accounting for the highest proportion (19\%) followed by axlebox failure (18\%). In another project (Regazzi et al., 2019) based on the data provided by Havelländische Eisenbahn AG (HVLE), Germany, researchers used the failure mode and effect analysis (FMEA) method to analyze the likelihood of seven RSFs including axle crack, wheel out-of-round, wheel 
crack, wheel build-up material, wheel thermomechanical crack, wheel flat, and wrong tread profile. The results showed that among these seven failures, the occurrence probabilities of the wheel out-of-round and the wheel flat are the highest, both are approximately 0.06 .

Due to limited data and a limited range of vehicle types, these statistics may not reflect the status of the entire railway industry. However, they do show that the wheel flat is one of the most critical RSFs: the large impact force induced by structural discontinuity on the wheel flat area will accelerate the deterioration of infrastructure elements such as rails, sleepers, fasteners, and other components (Appel and Hecht, 2017; Mitusch and Hecht, 2017; Bosso et al., 2018).

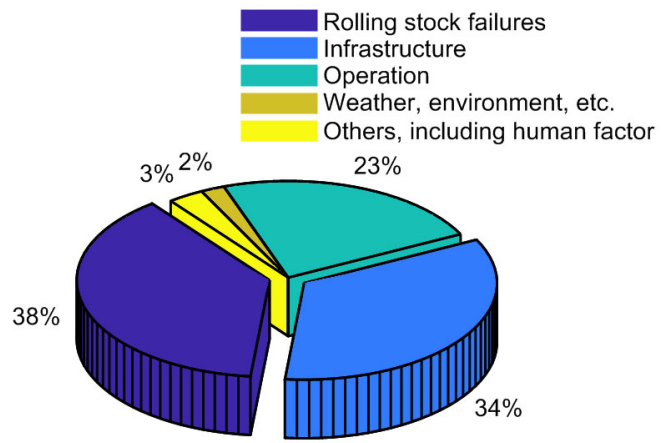

(a)

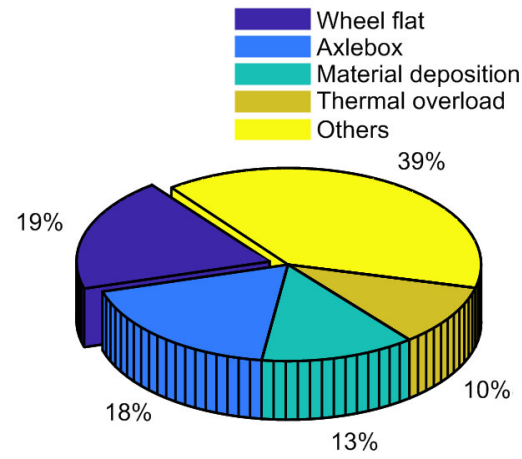

(b)

Fig. 1 Derailment causes and their percentages (a) and most frequently discovered defects in the rolling gear (b)

\subsection{Motivation}

Current simulation-based track charging models and track friendliness evaluation models are based on the quantitative indexes of track deterioration mechanisms such as TS, TCF, AW, and RCF. However, the abnormal interaction between rolling stock and infrastructure, which could be caused by RSFs, are not considered. Our work, which was initiated by the Assets4Rail Project, focuses on quantifying specific RSF effects on railway infrastructure to help IMs better understand the influence of RSFs on infrastructure deterioration and vehicle abnormalities on track access charge.

The wheel flat is a common RSF with wellestablished length standards for operational limits (e.g. the $40-\mathrm{mm}$ standard specified by the Italian railways (Belotti et al., 2006)). However, in actual operation, the size of wheel flats can be smaller than the specified criteria, and such flats are difficult to be completely erased by normal wheel-rail wear, resulting in a long-term cyclic WR impact, in turn exacerbating track deterioration. Quantifying the influence of wheel flats on track deterioration allows better safety management and investment decisions, ultimately benefiting the competitive success of railways.

\subsection{Quantification method}

\subsubsection{Quantification indexes}

The first stage in our methods involves a multibody dynamics simulation (MBS) in which we built a Bo-Bo locomotive with a wheel flat failure and operated it on a straight track to produce estimates of the four damage mechanisms (TS, TCF, AW, and RCF). We used four indexes $\left(q_{\mathrm{TS}}, q_{\mathrm{TCF}}, q_{\mathrm{AW}}\right.$, and $\left.q_{\mathrm{RCF}}\right)$ to quantify the severity of these damage mechanisms.

\subsubsection{Surrogate modeling}

The second stage involves the creation of a quantitative model to describe the influence of vehicle speed and wheel flat length on track deterioration, where the Kriging surrogate model (KSM) technique is introduced.

Simulations involving parametric studies are often based on repetitive modeling, which significantly increase the calculation complexity and load; these calculations are in fact so complex that the railway industry is reluctant to do many deterministic analyses. Part of the research goal was to find a high-efficiency and reliable method to simplify simulation procedures to reduce the number of uncertainties and decrease the probability of errors (Ye et al., 2020b, 2020c). KSM, as a regression model, is introduced to reduce simulation times (Chowdhury and Adhikari, 2012). 


\section{Locomotive/track coupled dynamics model}

\subsection{Locomotive model}

The Bo-Bo locomotive (Tao et al., 2018) modeled in this section includes three substructures: one car body and two bogies. The bogie has two stages of suspensions, i.e. the primary suspension and the secondary suspension (Fig. 2).

The primary suspension includes:

1. Two flexi-coil springs (each axlebox) to provide the vertical stiffness;

2. A vertical damper to slow down the impact;

3. A longitudinal rod to provide the main longitudinal stiffness and transmit the traction and braking force from the wheelset to the bogie frame;

4. A lateral bump stop to limit the lateral displacement of the axlebox;

5. A vertical bump stop to limit the vertical displacement of the axlebox.

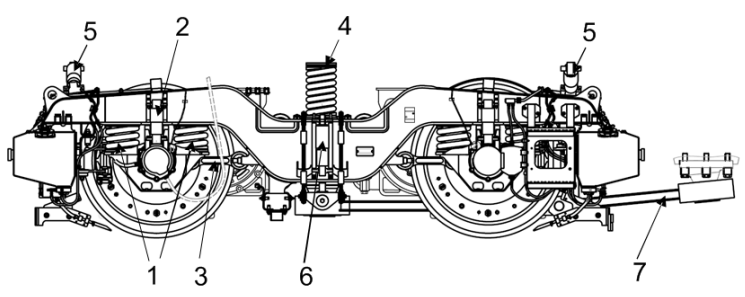

Fig. 2 Side elevation of the bogie

1: primary suspension flexi-coil spring; 2 : primary suspension vertical damper; 3: axlebox longitudinal rod; 4: secondary suspension flexi-coil spring; 5: secondary suspension lateral damper; 6: secondary suspension vertical damper; 7: traction rod. Reprinted from (Tao et al., 2018), Copyright 2018, with permission from Springer

The secondary suspension includes:

1. Six flexi-coil springs arranged in the middle of the bogie frame (three for each side) to provide the stiffness in three directions (longitudinal, lateral, and vertical).

2. Two lateral dampers located at the two ends of the bogie frame (one for each end) to reduce the lateral vibration of the carbody. These dampers also provide anti-rotary torque to limit the yaw motion of the bogie and have a similar function of the anti-yaw damper that is not included in this bogie.
3. Two vertical dampers arranged at the two sides of the bogie (one for each side) to reduce the vertical vibration from the bogie to the carbody.

4. A traction rod to transmit the longitudinal force.

5. A lateral bump stop to limit the lateral displacement of the bogie.

6. A vertical bump stop to limit the vertical displacement of the bogie.

\subsection{Wheelset-track model}

Wheelset structural flexibility and track flexibility are two main factors that contribute to highfrequency WR forces and affect track deterioration (Chaar and Berg, 2006). In addition, the wheel flat-induced forces may contribute to the elastic deformation of the wheelset (Wu et al., 2018; Ye et al., 2020a). Therefore, the wheelset is modeled as a flexible body on the basis of the finite element method (FEM), and the first 26 eigenmodes belonging to eigen-frequencies below $1 \mathrm{kHz}$ are imported into SIMPACK. Fig. 3 presents some of the flexible mode shapes of the wheelset together with the corresponding frequencies. The detailed derivation process of the motion equation to describe the flexible wheelset refers to Baeza et al. (2008) and Han et al. (2018).

For the modeling of the track, on one hand, simulating the track according to the real situation (i.e. the form of rail+sleeper+track bed+subgrade) will involve many degrees of freedom, thereby increasing the calculation amount especially when coupled with flexible wheelsets. On the other hand, track flexibility contributes to high-frequency WR forces. For these reasons and others (Chaar and Berg, 2006), we simplified the track model as a moving track with a form of rail+sleeper+ground (Fig. 4), which is convenient for simulating long travel distances. This simplification is acceptable because the required outputs are the WR lateral force, longitudinal force, and wear number, and the internal forces of the track are not considered. The ERRI B176 spectrum integrated in SIMPACK is applied as the track irregularities.

In this model, the power spectral density (PSD) of the typical European spectrum (ERRI B176) defined in SIMPACK is applied as the track irregularities. 


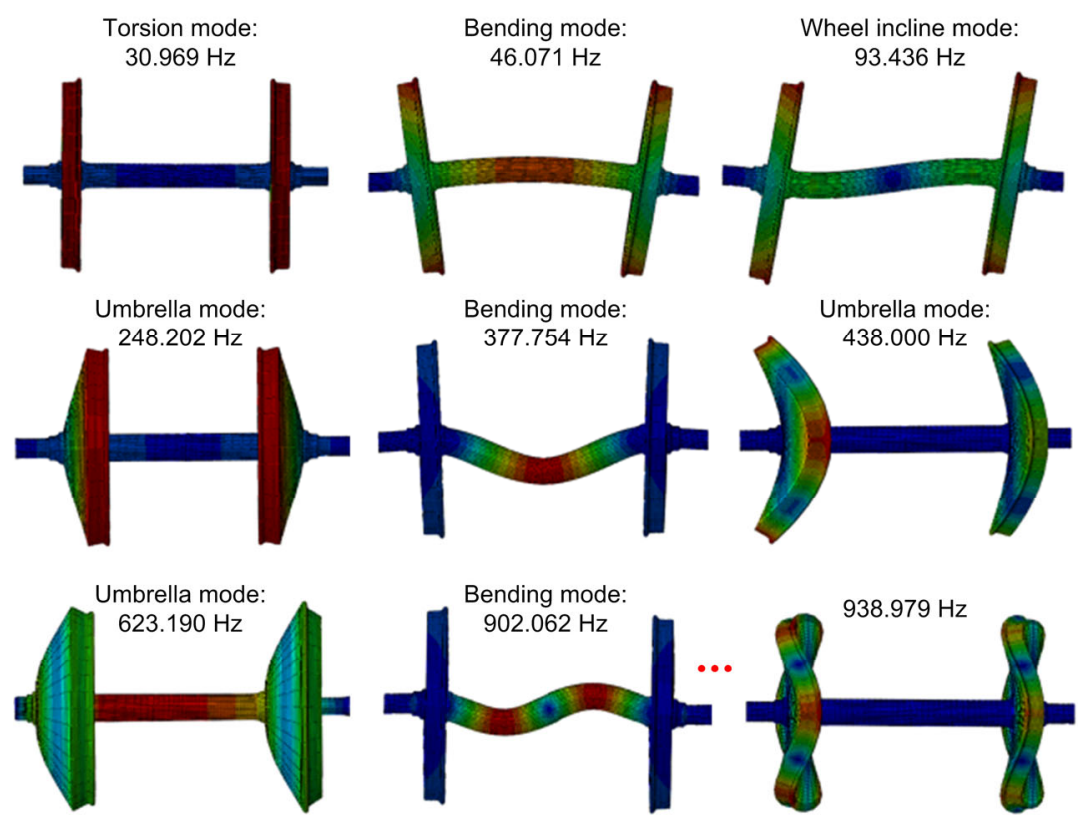

Fig. 3 Selected vibration modes of the flexible wheelset together with the corresponding frequencies

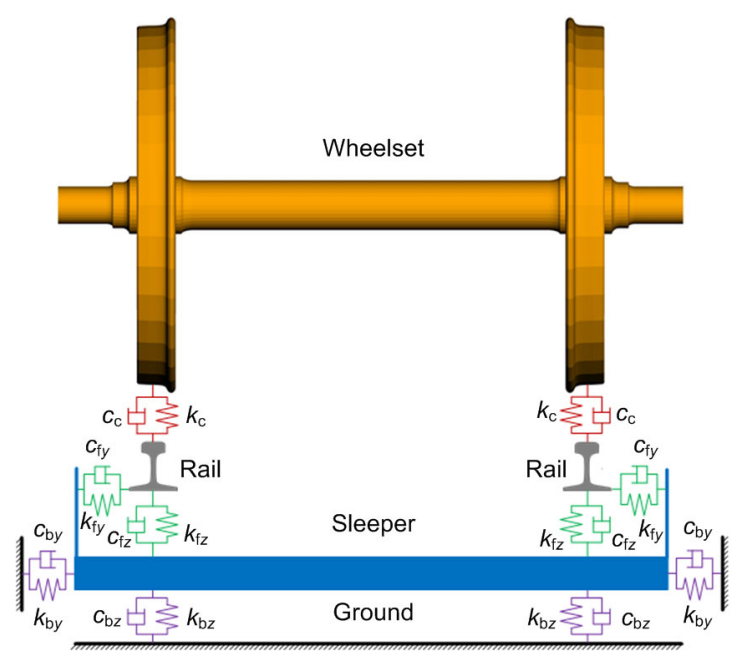

Fig. 4 Topology of the wheelset-track model (Explanations of the variables are listed in Appendix A)

\subsection{Wheel flat model}

As mentioned in Section 1.2, the wheel flat is one of the most common RSFs. It is therefore introduced as a case to study the influence of RSFs on track deterioration. Referring to Lyon (1972), the wheel flat (Fig. 5a) is modeled as a haversine wheel flat and expressed as

$$
\Delta d=-\frac{1}{2} d_{\mathrm{f}}\left[1-\cos \frac{2 \pi x_{\mathrm{f}}}{L_{\mathrm{f}}}\right]
$$

where $\Delta d$ denotes the variation in radius, $L_{\mathrm{f}}$ denotes the flat length, $x_{\mathrm{f}}$ denotes the distance along the flat, $d_{\mathrm{f}}=L_{\mathrm{f}}^{2} /(16 R)$ denotes the flat depth, and $R$ denotes the wheel radius. In Fig. 5a, $\Psi$ denotes the angular size of the wheel flat, and $\omega$ denotes the angular coordinate. In this paper, eight different wheel flats lengths $\left(L_{\mathrm{f}}\right)$ are simulated (Fig. $5 \mathrm{~b}$ ), which are $5 \mathrm{~mm}$, $10 \mathrm{~mm}, 15 \mathrm{~mm}, 20 \mathrm{~mm}, 25 \mathrm{~mm}, 30 \mathrm{~mm}, 35 \mathrm{~mm}$, and $40 \mathrm{~mm}$, respectively.

The final vehicle model, as well as the bogie model, simulated in SIMPACK is shown in Fig. 6. The parameters of interest are listed in Appendix A.

\section{Methodology}

\subsection{Track deterioration model}

Öberg (2006)'s review of 21 track deterioration models concerning ballasted tracks showed few track deterioration models dealt with several mechanisms of track deterioration. Smith et al. (2015) used a track deterioration model that considers four mechanisms (TS, TCF, AW, and RCF) to determine track access charges; this same track deterioration model was used to evaluate the track friendliness of different vehicles (Bruni et al., 2016). We use these four mechanisms in our work. 


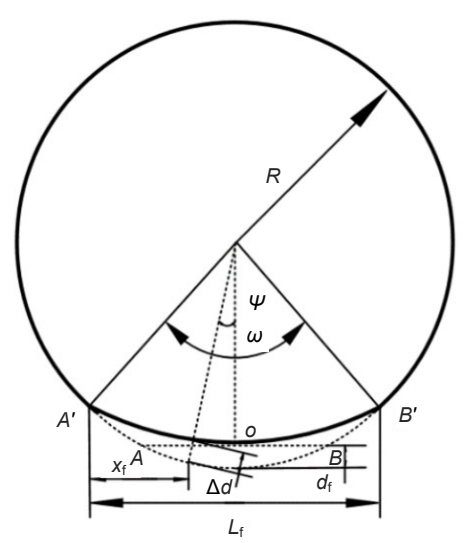

(a)

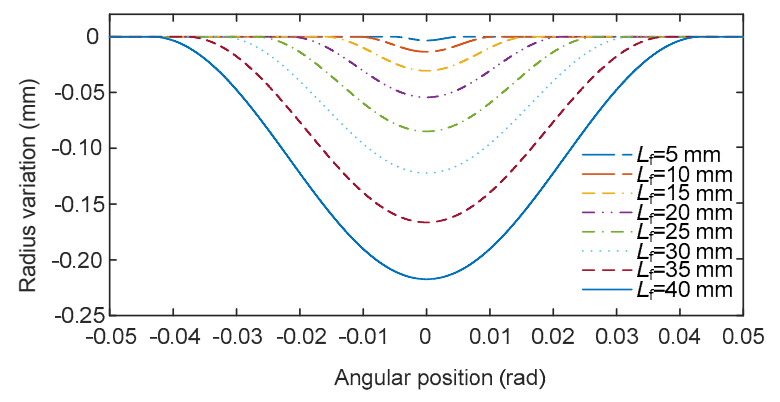

(b)

Fig. 5 Geometry of the wheel flat (a) and eight simulated wheel flats (b)

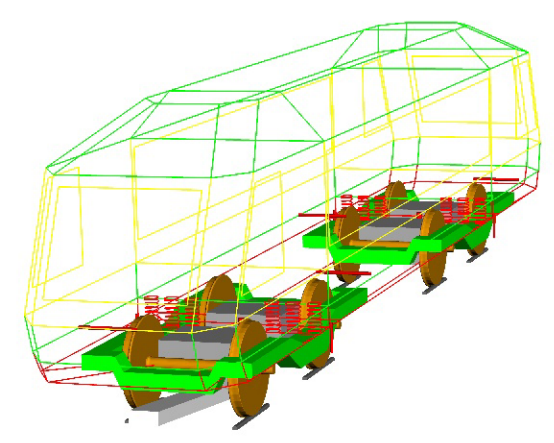

(a)

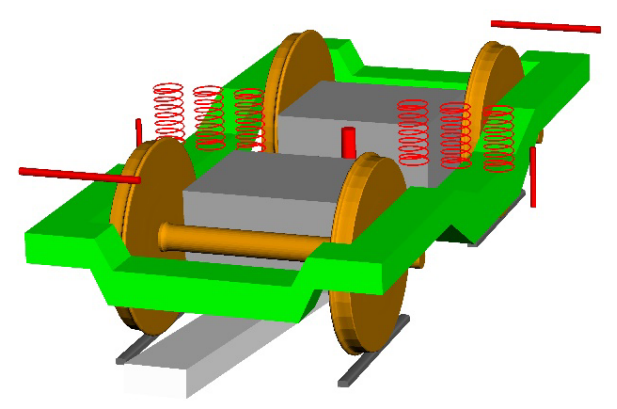

(b)

Fig. 6 Locomotive wagon (a) and bogie (b)

\subsubsection{Track settlement (TS)}

TS consists of ballast settlement, sub-ballast settlement, and subgrade settlement, of which the ballast settlement plays the most important role in track degradation (Shenton, 1984; Chrismer and Selig, 1993). Many models have been used to predict TS (Elkhoury et al. 2018). The basis of the introduced TS model here is the ballast settlement model defined by the Technische Universität München (TUM), Germany. Referring to Smith et al. (2015), a simplified model is used in our work.

The TUM model is defined by

$$
T_{\mathrm{s}}=A p \ln \Delta N+B p^{1.21} \ln N,
$$

where $T_{\mathrm{s}}$ is the TS index (mm), $N$ is the number of axle passes, $\Delta N$ is the number of axles passes $\leq 10000$ after tamping, $p$ is the ballast pressure $\left(\mathrm{N} / \mathrm{mm}^{2}\right)$, and $A$ and $B$ are constants.

The simplified model can be represented by

$$
T_{\mathrm{s}}=A^{*} Q^{1.21} \lg N,
$$

where $Q$ is the maximum vertical force at the wheelset, and $A^{*}$ is a constant. In this paper, $A^{*}=1$.

\subsubsection{Track component fatigue (TCF)}

TCF refers to internal fatigue of components such as rails, sleepers, fasteners, ballast, and other mechanisms as well as abrasive wear and RCF of rails (referred to as surface fatigue of rails) (Öberg and Andersson, 2009). TCF is affected by repeated loads in which the vertical and lateral track forces have the greatest impact. The TCF index introduced here was developed by UIC/ORE based on extensive full-scale tests during the 1980s, and is expressed as a function of vertical and lateral track forces, as shown in Eq. (4):

$$
T_{\mathrm{cf}}=\sum_{i=1}^{N}\left(Q_{\mathrm{tot}_{i}}^{2}+Y_{\mathrm{qst}_{i}}^{2}\right)^{1.5},
$$

where $T_{\mathrm{cf}}$ is the TCF index, $Q_{\mathrm{tot}_{i}}$ is the total vertical force including quasi-static and dynamic forces, and $Y_{\mathrm{qst}_{i}}$ is the quasi-static lateral force. 


\subsubsection{Abrasive wear (AW)}

The wear amount is taken as a function of material properties, contact pressures, creepages, sliding velocities, and environmental conditions. Currently, there are many $T \gamma$-based models that can be used to calculate the material loss of railway wheels (Pearce and Sherratt, 1991; Zobory, 1997; Braghin et al., 2006; Enblom, 2009; Pombo et al., 2011; Tao et al., 2017; Peng et al., 2019; Ye et al., 2020d), such as the British Rail Research (BRR) model, Zobory model, University of Sheffield (USFD) model. In these models, the first step is to calculate the product of the tangential force $(T)$ and the creepage $(\gamma)$ in the WR contact patch, i.e. $T \gamma$, which is given by

$$
T \gamma=F_{x} v_{x}+F_{y} v_{y}+M \varphi,
$$

where $F_{x}$ and $F_{y}$ are longitudinal and lateral creep forces, $v_{x}$ and $v_{y}$ are longitudinal and lateral creepages, respectively, $M$ is the moment, and $\varphi$ is the spin.

\subsubsection{Rolling contact fatigue (RCF)}

Rolling contact creates both elastic and plastic deformations in the contact area, alternating stress that leads to fatigue damage with a correspondingly high number of cycles. In the rail vehicle sector, damage caused in this way is referred to as RCF. According to Burstow (2003) and Smith et al. (2016), the RCF damage index on the rail surface is also calculated based on the $T \gamma$ value, as shown in Fig. 7.

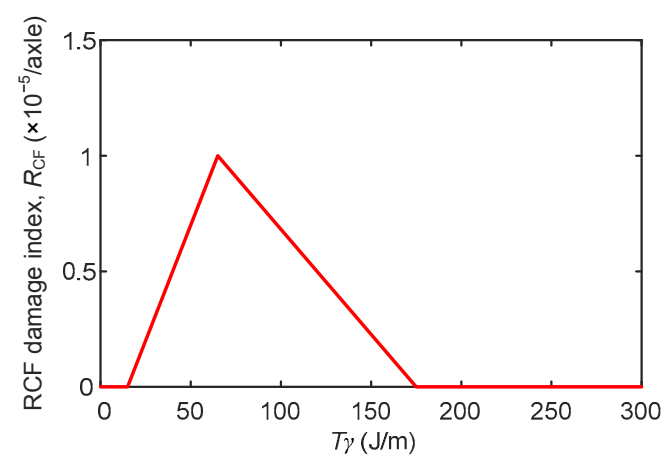

Fig. 7 Rail RCF damage function

1. Below $15 \mathrm{~J} / \mathrm{m}$ (or $\mathrm{N}$ ), the energy is insufficient to initiate the RCF cracks.

2. Above $15 \mathrm{~J} / \mathrm{m}$, the damge increases to a maximum of $1 \times 10^{-5} /$ axle at a $T \gamma$ value of $65 \mathrm{~J} / \mathrm{m}$.
3. As $T \gamma$ increases from 65 to $175 \mathrm{~J} / \mathrm{m}$, the level of energy is such that the dominant form of surface damage is the wear (rather than the crack initiation).

4. $T \gamma$ values greater than $175 \mathrm{~J} / \mathrm{m}$ result in wear but no RCF initiation.

5. The unit of the RCF damage index is $10^{-5} /$ axle.

\subsection{Kriging surrogate model (KSM)}

KSM consists of a global regression model and a random correlation function. It is assumed that the response value corresponding to the sample point group $\boldsymbol{x}=\left[\boldsymbol{x}^{(1)}, \boldsymbol{x}^{(2)}, \ldots, \boldsymbol{x}^{(n)}\right]$ is $\boldsymbol{Y}=\left[y_{1}, y_{2}, \ldots, y_{n}\right], \boldsymbol{Y}$ is the response vector, and $n$ is the length of the vector. The relationship between the input variable and its response then is expressed as (Ye and Sun, 2020; Ye et al., 2020d):

$$
y(\boldsymbol{x})=\boldsymbol{f}^{\mathrm{T}}(\boldsymbol{x}) \beta+Z(\boldsymbol{x}),
$$

where $y(\boldsymbol{x})$ is the response, $\boldsymbol{f}^{\mathrm{T}}(\boldsymbol{x})$ is the regression model founded by the known function that depends on $\boldsymbol{x}, \beta$ is an undetermined coefficient, and $Z(\boldsymbol{x})$ is a random Gaussian distribution with a mean of zero and variance of $\sigma^{2}$. The covariance matrix of $Z(\boldsymbol{x})$ for an $m$-variable design space can be expressed as (Ye and Sun, 2020)

$$
\begin{aligned}
& \operatorname{Cov}\left[Z\left(\boldsymbol{x}^{(i)}\right), Z\left(\boldsymbol{x}^{(j)}\right)\right]=\sigma^{2} R\left(\boldsymbol{\theta}, \boldsymbol{x}^{(i)}, \boldsymbol{x}^{(j)}\right), \\
& R\left(\boldsymbol{\theta}, \boldsymbol{x}^{(i)}, \boldsymbol{x}^{(j)}\right)=\exp \left[-\sum_{l=1}^{m} \theta_{l}\left|x_{l}^{(i)}-x_{l}^{(j)}\right|^{2}\right],
\end{aligned}
$$

where $\boldsymbol{x}^{(i)}$ and $\boldsymbol{x}^{(j)}$ are two sample points in the sample space, and $1 \leq i, j \leq n ; R\left(\boldsymbol{\theta}, \boldsymbol{x}^{(i)}, \boldsymbol{x}^{(j)}\right)$ represents the spatial correlation between the sample points $\boldsymbol{x}^{(i)}$ and $\boldsymbol{x}^{(j)}$; $\left|x_{l}^{(i)}-x_{l}^{(j)}\right|$ represents the absolute distance between the $l$ th components of $\boldsymbol{x}^{(i)}$ and $\boldsymbol{x}^{(j)} ; \theta_{l}$ is the $l$ th component of $\boldsymbol{\theta}$ which indicates how active a variable is in the surrogate model. Larger values of $\theta_{l}$ can be interpreted as high-level of activity while smaller values of $\theta_{l}$ indicate that the variable can be ignored in the surrogate model ( $1 \leq l \leq 2$ in this paper). Therefore, a correlation matrix between the sample points and their response values can be obtained as (Ye and Sun, 2020) 
$\boldsymbol{R}=\left[\begin{array}{cccc}R\left(\boldsymbol{\theta}, \boldsymbol{x}^{(1)}, \boldsymbol{x}^{(1)}\right) & R\left(\boldsymbol{\theta}, \boldsymbol{x}^{(1)}, \boldsymbol{x}^{(2)}\right) & \ldots & R\left(\boldsymbol{\theta}, \boldsymbol{x}^{(1)}, \boldsymbol{x}^{(n)}\right) \\ R\left(\boldsymbol{\theta}, \boldsymbol{x}^{(2)}, \boldsymbol{x}^{(1)}\right) & R\left(\boldsymbol{\theta}, \boldsymbol{x}^{(2)}, \boldsymbol{x}^{(2)}\right) & \ldots & R\left(\boldsymbol{\theta}, \boldsymbol{x}^{(2)}, \boldsymbol{x}^{(n)}\right) \\ \vdots & \vdots & \ddots & \vdots \\ R\left(\boldsymbol{\theta}, \boldsymbol{x}^{(n)}, \boldsymbol{x}^{(1)}\right) & R\left(\boldsymbol{\theta}, \boldsymbol{x}^{(n)}, \boldsymbol{x}^{(2)}\right) & \ldots & R\left(\boldsymbol{\theta}, \boldsymbol{x}^{(n)}, \boldsymbol{x}^{(n)}\right)\end{array}\right]$

Therefore, the value of $\boldsymbol{\theta}$ needs to be determined first, calculated by maximizing the likelihood estimate of the response value as

$$
\begin{aligned}
\ln \boldsymbol{\theta}=- & \frac{1}{2}\left[n \ln \hat{\sigma}^{2}+\ln |\boldsymbol{R}|\right. \\
& \left.+\frac{1}{\hat{\sigma}^{2}}\left(\boldsymbol{Y}-\boldsymbol{f}^{\mathrm{T}} \hat{\boldsymbol{\beta}}\right)^{\mathrm{T}} \boldsymbol{R}^{-1}\left(\boldsymbol{Y}-\boldsymbol{f}^{\mathrm{T}} \hat{\boldsymbol{\beta}}\right)\right] .
\end{aligned}
$$

The estimate of $\boldsymbol{\theta}$ depends on the estimated undetermined coefficient matrix $\hat{\boldsymbol{\beta}}$ and the estimated variance $\hat{\sigma}^{2} . \hat{\boldsymbol{\beta}}$ and $\hat{\sigma}^{2}$ can be calculated using the generalized least square method, given as

$$
\begin{aligned}
& \hat{\boldsymbol{\beta}}=\left(\boldsymbol{F}^{\mathrm{T}} \boldsymbol{R}^{-1} \boldsymbol{F}\right)^{-1}\left(\boldsymbol{F}^{\mathrm{T}} \boldsymbol{R}^{-1} \boldsymbol{Y}\right), \\
& \hat{\sigma}^{2}=\frac{1}{n}\left(\boldsymbol{Y}-\boldsymbol{F}^{\mathrm{T}} \hat{\boldsymbol{\beta}}\right)^{\mathrm{T}} \boldsymbol{R}^{-1}\left(\boldsymbol{Y}-\boldsymbol{F}^{\mathrm{T}} \hat{\boldsymbol{\beta}}\right),
\end{aligned}
$$

where $\boldsymbol{F}=\left[f\left(\boldsymbol{x}^{(1)}\right), f\left(\boldsymbol{x}^{(2)}\right), \ldots, f\left(\boldsymbol{x}^{(n)}\right)\right]^{\mathrm{T}}$. For the final determined value of $\boldsymbol{\theta}$ please see Section 4.2.

Finally, after determining the input information of the unknown point $\boldsymbol{x}^{*}$, the corresponding response value can be predicted by the KSM using

$$
\hat{y}\left(\boldsymbol{x}^{*}\right)=\boldsymbol{F}^{\mathrm{T}}\left(\boldsymbol{x}^{*}\right) \hat{\boldsymbol{\beta}}+\boldsymbol{r}\left(\boldsymbol{x}^{*}\right)^{\mathrm{T}} \boldsymbol{R}^{-1}(\boldsymbol{Y}-\boldsymbol{F} \hat{\boldsymbol{\beta}}),
$$

where $\boldsymbol{r}\left(\boldsymbol{x}^{*}\right)=\left[R\left(\boldsymbol{\theta}, \boldsymbol{x}^{*}, \boldsymbol{x}^{(1)}\right), R\left(\boldsymbol{\theta}, \boldsymbol{x}^{*}, \boldsymbol{x}^{(2)}\right), \ldots, R\left(\boldsymbol{\theta}, \boldsymbol{x}^{*}\right.\right.$, $\left.\boldsymbol{x}^{(n)}\right)$ ] is the correlation function vector of the sample point to be tested and each known sample point. The mean squared error (MSE), which is again dependent on $\boldsymbol{r}$, is used to measure the uncertainty of the predicted value:

$$
\hat{s}^{2}\left(\boldsymbol{x}^{*}\right)=\hat{\sigma}^{2}\left[1-\boldsymbol{r}^{\mathrm{T}} \boldsymbol{R}^{-1} \boldsymbol{r}+\frac{\left(1-\mathbf{1}^{\mathrm{T}} \boldsymbol{R}^{-1} \boldsymbol{r}\right)^{2}}{\mathbf{1}^{\mathrm{T}} \boldsymbol{R}^{-1} \boldsymbol{r}}\right] .
$$

The square root of Eq. (13) (RMSE) is used to measure the accuracy of the established model over the design space. The uniform experimental design sampling principle (Xin et al., 2017) is used to select the sample points in our work.

\subsection{Technique route}

The technique route of this method is shown in Fig. 8. The simulation steps are summarized as follows:

Step 1: Select sample: the corresponding wheel flat lengths and the vehicle speeds are selected according to the uniform experimental design sampling principle.

Step 2: The wheel flat curve is constructed and imported into the MBS model.

Step 3: Run the short-term simulation in SIMPACK and generate wheel-rail vertical force, wheel-rail lateral force, wear number, etc.

Step 4: Calculate the total loss of each of the four mechanisms (TS, TCF, AW, and RCF).

Step 5: Four quantification indicators (see Section 4.1) are introduced to quantify the influence of wheel flats on track deterioration.

Step 6: A KSM-based quantification model is built.

\section{Simulation results}

MBS results are required for the damage calculation using the deterioration mechanisms mentioned in Section 3.1. To study the severity of track deterioration with the change of vehicle speed and wheel flat length, we did simulations of seven different vehicle speeds $v(30 \mathrm{~km} / \mathrm{h}, 40 \mathrm{~km} / \mathrm{h}, \ldots, 90 \mathrm{~km} / \mathrm{h})$, and under each speed, the wheel flat length $L$ goes from 0 to $40 \mathrm{~mm}$ in an increment of $5 \mathrm{~mm}(0 \mathrm{~mm}, 5 \mathrm{~mm}, \ldots$, $40 \mathrm{~mm}$, Fig. 6c), with a total of 63 simulations. The wheel flat is created on the right wheel of the first wheelset with the help of the untrueness modeling capability of the SIMPACK.

It should be noted that the calculation time step needs to be discreetly chosen, especially for such shock signals arising from wheel flats. Like other computerized calculation tools, SIMPACK is limited to the numerical methods' precision and inherent errors. Whilst the calculation time step is reduced, the 'resolution' of the simulation results is enhanced, and the overall time to perform the simulation is extended. Considering both the precision and computational 


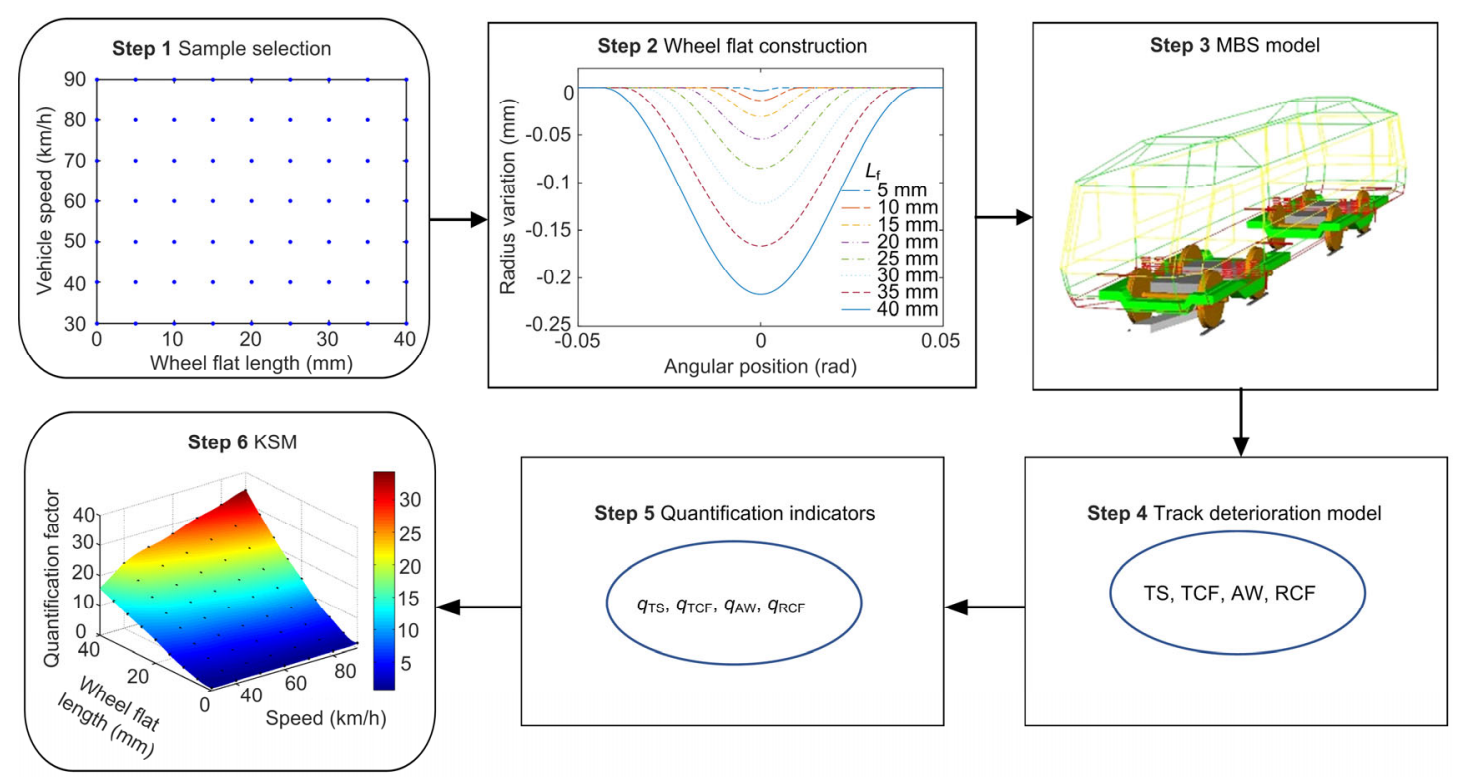

Fig. 8 Technique route of the quantification model

effort, $0.05 \mathrm{~ms}$ is used in this work referring to Bernal et al. (2019).

\subsection{Quantification indicators}

This work was done to study the effect of trains with wheel flats on track deterioration relative to normal trains. Four relative quantification indicators are used to evaluate the effects of wheel flats on TS, $\mathrm{TCF}, \mathrm{AW}$, and $\mathrm{RCF}\left(q_{\mathrm{TS}}, q_{\mathrm{TCF}}, q_{\mathrm{AW}}\right.$, and $\left.q_{\mathrm{RCF}}\right)$. Among them, $q_{\mathrm{TS}}$ is defined by

$$
q_{\mathrm{TS}}=\frac{T_{\mathrm{sf}}}{T_{\mathrm{so}}}=\left(\frac{Q_{\mathrm{sf}}}{Q_{\mathrm{so}}}\right)^{1.21},
$$

where $T_{\mathrm{sf}}$ is the TS caused by the train with a wheel flat; $T_{\text {so }}$ is the TS caused by a normal train with a speed of $30 \mathrm{~km} / \mathrm{h} ; Q_{\text {sf }}$ is the WR vertical peak force caused by the train with a wheel flat; $Q_{\text {so }}$ is the WR vertical peak force caused by the normal train with a speed of $30 \mathrm{~km} / \mathrm{h}$.

According to Eq. (14), it can be known that in simulation, the most important indicator for solving the TS is the WR vertical peak force $Q$. The WR vertical peak force, however, could be affected by track irregularities. Also, the vehicle-track system has many nonlinear factors including characteristics of yaw dampers and suspensions, as well as the geometric contact characteristics of wheels and rails. Therefore, the peaks of the WR vertical peak forces generally during each wheel rotation period, usually are unequal, as shown in Fig. 9a. Based on these considerations, we used the average of the peak as the WR vertical peak force $Q_{\text {sf }}$, calculated by

$$
Q_{\mathrm{sf}}=\frac{A_{1}+A_{2}+\cdots+A_{k}}{k}
$$

where $A_{i}(i=1,2, \ldots, k)$ represents the WR vertical peak force at the $i$ th wheel rotation, and $k$ represents the number of wheel rotations.

$q_{\mathrm{TCF}}$ can be calculated by

$$
q_{\mathrm{TCF}}=\frac{T_{\mathrm{cff}}}{T_{\mathrm{cfo}}},
$$

where $T_{\text {cff }}$ is the TCF caused by the train with a wheel flat; $T_{\text {cfo }}$ is the TCF caused by the normal train with a speed of $30 \mathrm{~km} / \mathrm{h}$.

$q_{\mathrm{AW}}$ is calculated by

$$
q_{\mathrm{AW}}=\frac{T \gamma_{\mathrm{f}}}{T \gamma_{\mathrm{o}}},
$$

where $T \gamma_{\mathrm{f}}$ is the AW caused by the train with a wheel 
flat; $T \gamma_{0}$ is the AW caused by the normal train with a speed of $30 \mathrm{~km} / \mathrm{h}$, as shown in Fig. $9 \mathrm{~b}$.

As mentioned in Section 3.1.4, when the $T \gamma$ value is below $15 \mathrm{~J} / \mathrm{m}$, the energy is insufficient to initiate the RCF cracks, which means that RCF cracking may not happen on wheels if the wear number is below $15 \mathrm{~J} / \mathrm{m}$. This situation may occur in normal trains or trains with small wheel flats. Therefore, the relative quantitative indicator for RCF is itself.

$$
q_{\mathrm{RCF}}=R_{\mathrm{CF}} \text {. }
$$

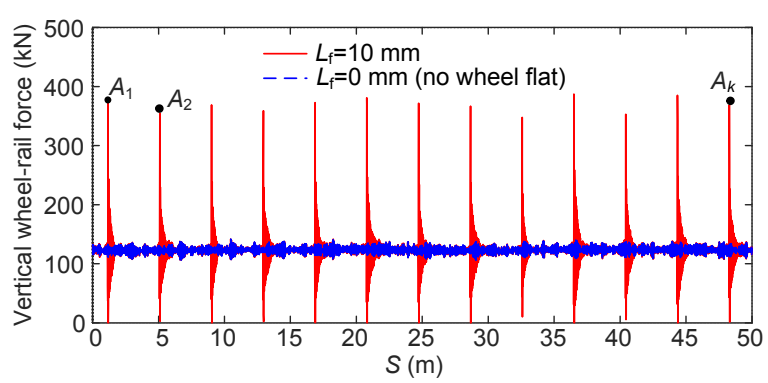

(a)

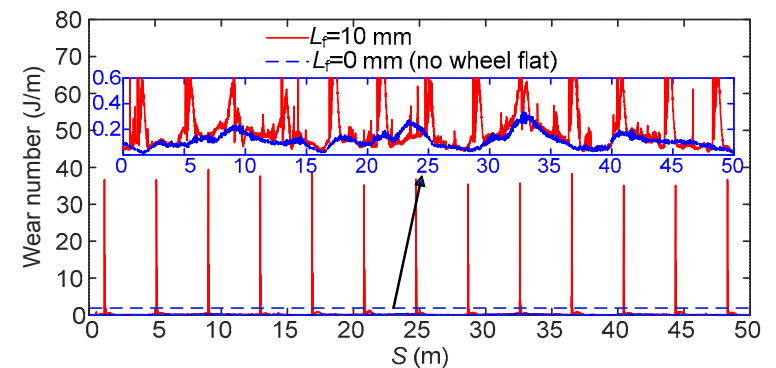

(b)

Fig. 9 Vertical force (a) and wear number (b) of the wheel with a wheel flat when the vehicle speed is $30 \mathrm{~km} / \mathrm{h}$ (simulated result), where $S$ represents the distance

\subsection{Simulation results}

Appendix B lists the original simulated results, including $Q, T_{\mathrm{cf}}, T \gamma$, and $R_{\mathrm{c} \text {. }}$ Based on these original data, the quantification indexes $q_{\mathrm{TS}}, q_{\mathrm{TCF}}, q_{\mathrm{AW}}$, and $q_{\text {RCF }}$ can be calculated by Eqs. (14), (16), (17), and (18), respectively. In the construction of the KSM model, the length of wheel flat $\left(L_{\mathrm{f}}\right)$ and vehicle speed (v) are set as the inputs of KSM, while $q_{\mathrm{TS}}, q_{\mathrm{TCF}}, q_{\mathrm{AW}}$, and $q_{\mathrm{RCF}}$ are set as the output responses, respectively, i.e. $x=\left[L_{\mathrm{f}}, v\right]$, and $y(x)=q_{\mathrm{TS}}, y(x)=q_{\mathrm{TCF}}, y(x)=q_{\mathrm{AW}}$ or $y(x)=q_{\mathrm{RCF}}$ in Eq. (6). Then, the values of $\boldsymbol{\theta}$ (Eq. (9)) and $R$ (Eq. (7)) of the surrogate model can be derived.
Finally, the established KSM concerning $q_{\mathrm{TS}}, q_{\mathrm{TCF}}$, $q_{\mathrm{AW}}$, and $q_{\mathrm{RCF}}$ is shown in Fig. 10, in which the calculated values of $\boldsymbol{\theta}$ are $[1.25,1.25],[0.625,1.25]$, $[1.25,1.25]$, and $[2.5,1.7678]$, respectively. To ensure the correctness of the KSM, the accuracy of the KSM should be verified first. Fig. 11 displays the absolute value of RMSE value derived from Eq. (13). These four figures reveal that the errors on the edges and corners of the design space are larger than that in the central part, as shown in Fig. 11. However, these errors can be negligible, which means that these KSM models are accurate enough.

$q_{\mathrm{TS}}$ (Fig. 10a) shows an increase with the increase of vehicle speed and wheel flat length. When the vehicle speed is increased to $90 \mathrm{~km} / \mathrm{h}$ and the wheel flat length is increased to $40 \mathrm{~mm}$, the TS caused by the vehicle is about 35 times of the TS caused by the vehicle when the vehicle speed is $30 \mathrm{~km} / \mathrm{h}$ and the wheel flat length is $0 \mathrm{~mm}$. In terms of $q_{\mathrm{TCF}}$ (Fig. 10b) and $q_{\mathrm{AW}}$ (Fig. 10c), like the $q_{\mathrm{TS}}$, they also show a consistent increase with the increase of vehicle speed and wheel flat length. When the vehicle speed is increased to $90 \mathrm{~km} / \mathrm{h}$ and the wheel flat length is increased to $40 \mathrm{~mm}$, the TCF and AW caused by the vehicle are higher than 250 and 400 times, respectively, relative to that caused by the train with a speed of $30 \mathrm{~km} / \mathrm{h}$ and a wheel flat length of $0 \mathrm{~mm}$. This rising trend will become more pronounced as the vehicle speed and the length of wheel flat increase. The $q_{\text {RCF }}$ (Fig. 10d) at low speeds $(v<75 \mathrm{~km} / \mathrm{h})$ increases gradually as the wheel flat length increases; at high speeds $(v>75 \mathrm{~km} / \mathrm{h})$, it first increases sharply and then decreases gradually, reaching a maximum value of about 10 when the wheel flat length is close to $35 \mathrm{~mm}$.

Based on the above phenomena, we reach two conclusions:

1. The wheel flat has a serious impact on track deterioration. In general, $q_{\mathrm{TS}}, q_{\mathrm{TCF}}$, and $q_{\mathrm{AW}}$ increase with the increase of the wheel flat length and vehicle speed, and this increasing trend becomes more acute with the increase of the wheel flat length and vehicle speed. At low speeds, $q_{\mathrm{RCF}}$ increases as the wheel flat length increases; at high speeds, it first increases and then decreases. The reason for this phenomenon is that the value of $T \gamma$ increases with the increase of the wheel flat length and vehicle speed. When the increase of the wheel flat length and vehicle speed 
(a)

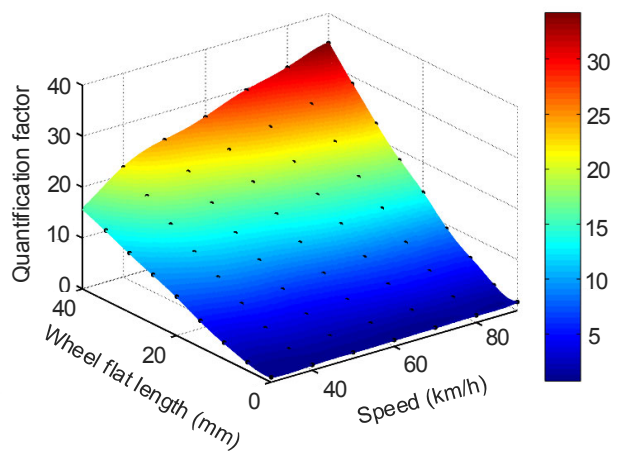

(b)

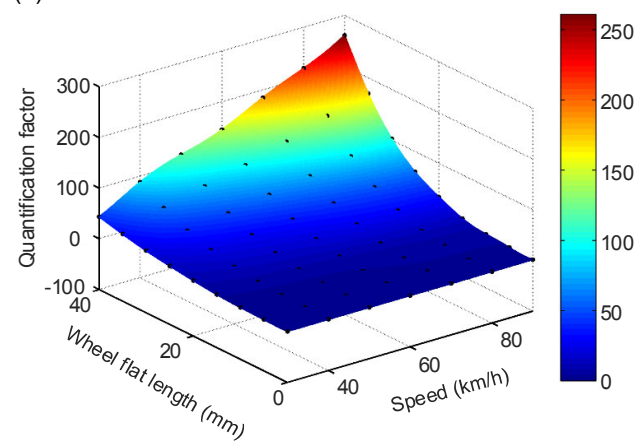

(c)

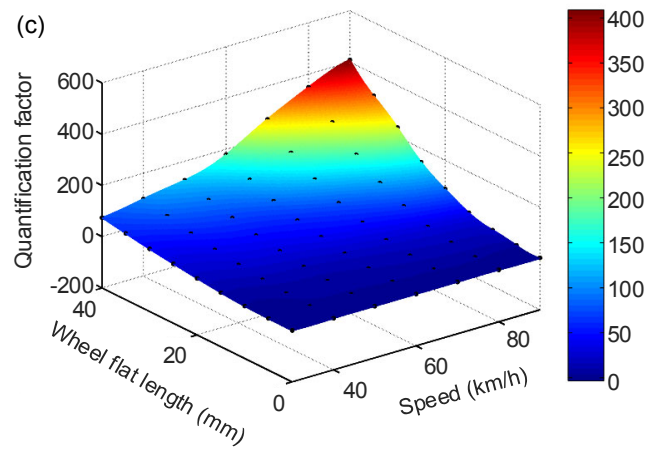

(d)

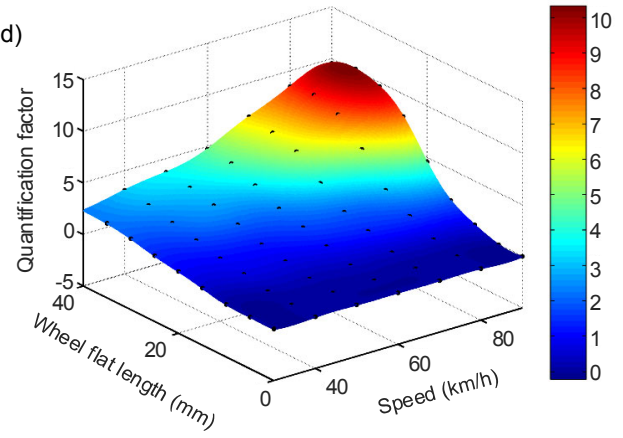

(a)

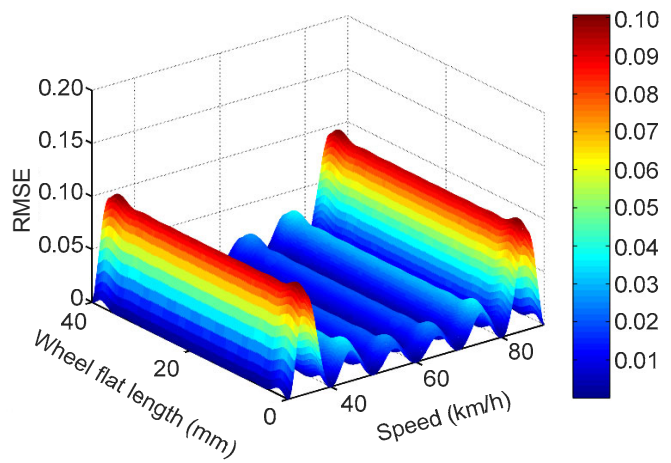

(b)

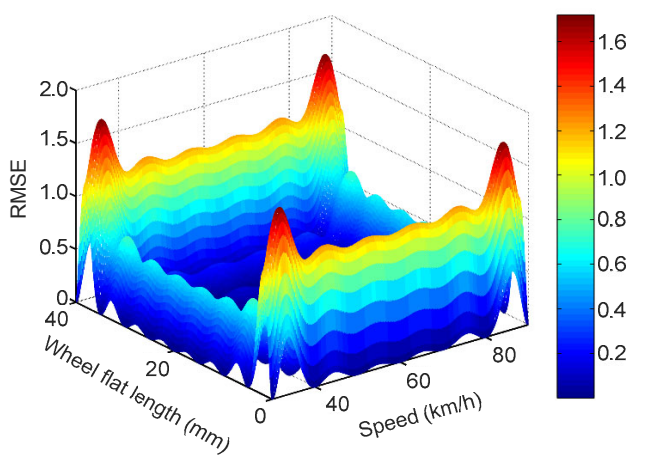

(c)
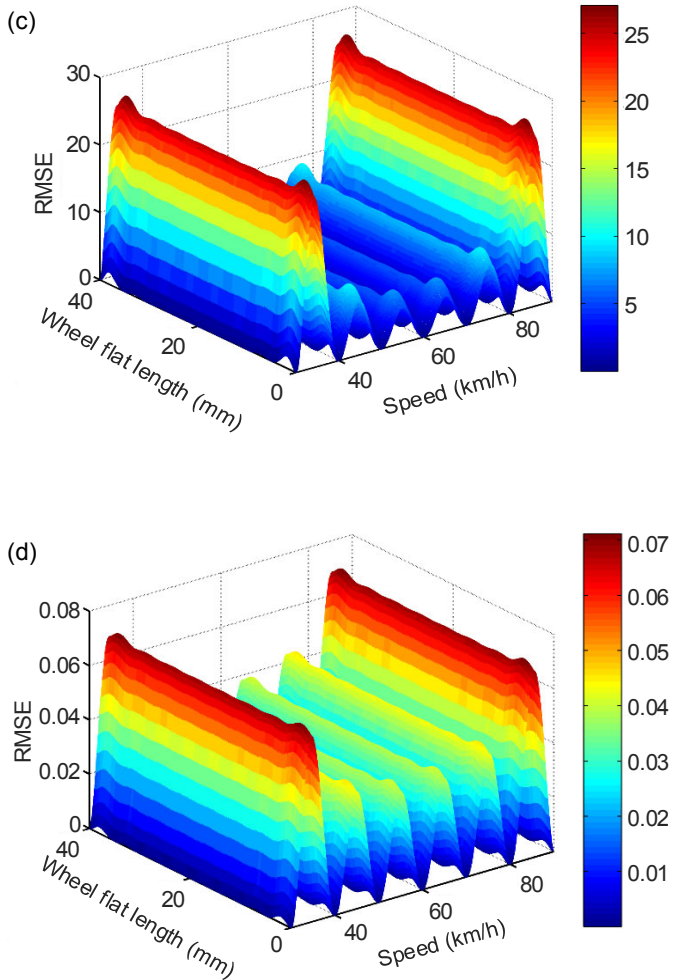

Fig. 11 RMSE results over the design space: (a) $q_{\mathrm{TS}}$, (b) $q_{\mathrm{TCF}}$, (c) $q_{\mathrm{AW}}$, and (d) $q_{\mathrm{RCF}}$
Fig. $10 \mathrm{KSM}$ results concerning: (a) $q_{\mathrm{TS}}$, (b) $q_{\mathrm{TCF}}$, (c) $q_{\mathrm{AW}}$, and (d) $q_{\mathrm{RCF}}$ 
causes $T \gamma$ to be greater than $65 \mathrm{~J} / \mathrm{m}$, due to the relationship in Fig. 7, $q_{\mathrm{RCF}}$ will not continue to increase. Specifically, when $65 \mathrm{~J} / \mathrm{m}<T \gamma<175 \mathrm{~J} / \mathrm{m}$, the main form of surface damage caused by energy levels is wear rather than crack initiation so that $q_{\mathrm{RCF}}$ decreases when wheel flat length and vehicle speed increase to a certain extent.

2. The influence of the wheel flat on $q_{\mathrm{TCF}}$ and $q_{\mathrm{AW}}$ is the most obvious, indicating that TCF and AW are the most sensitive to wheel flats. When the vehicle speed is increased to $90 \mathrm{~km} / \mathrm{h}$ and the wheel flat length is increased to $40 \mathrm{~mm}$, the TCF and AW caused by the vehicle are higher than 250 and 400 times, respectively, relative to that caused by the train with a speed of $30 \mathrm{~km} / \mathrm{h}$ and a wheel flat length of $0 \mathrm{~mm}$. Followed by TS, when the vehicle speed is increased to $90 \mathrm{~km} / \mathrm{h}$ and the wheel flat length is increased to $40 \mathrm{~mm}$, the TS caused by the vehicle is about 35 times of the TS caused by the normal vehicle with a speed of $30 \mathrm{~km} / \mathrm{h}$. Besides, the value of $q_{\mathrm{RCF}}$ is 0 when the vehicle speed is $30 \mathrm{~km} / \mathrm{h}$ and the wheel flat length is $0 \mathrm{~mm}$, and it increases to around 10 when the vehicle speed approaches $90 \mathrm{~km} / \mathrm{h}$ and the wheel flat length is close to $35 \mathrm{~mm}$.

\section{Conclusions and discussion}

Deterioration of rail tracks is an inevitable phenomenon of the railway infrastructure affected by traffic and climate and is one of the main concerns for train operators and infrastructure sectors. Understanding and quantifying the underlying engineering characteristics of rail track deterioration are critical aspects of improving train safety, advancing maintenance strategies, and optimizing track access charging. Today, however, current quantitative methods do not consider the anomalous interaction between rolling stock and infrastructure, which could be caused by RSFs. Taking the wheel flat, which is a common $\mathrm{RSF}$, as an example, this work used four quantification indicators to evaluate the track deterioration based on the KSM.

To date, track deterioration mechanisms are mainly classified into four categories: TS, TCF, AW, and RCF. In this work, four indicators are introduced to quantify the severity of these four damage mechanisms, namely $q_{\mathrm{TS}}, q_{\mathrm{TCF}}, q_{\mathrm{AW}}$, and $q_{\mathrm{RCF}}$, respectively. These four indicators can not only help us understand the influence of abnormal RSFs on track deterioration, but also provide a reference for the track charging models of infrastructure companies.

1. Based on a locomotive/track coupled dynamics model, our results show that the wheel flat has a significant influence on track deterioration. More specifically, TS, TCF, and AW increase sharply with the increase of the wheel flat length and the vehicle speed, and this increasing trend becomes more acute with the increase of the wheel flat length and the vehicle speed. At low speeds, RCF increases gradually as the wheel flat length increases; at high speeds, it increases sharply at first and then decreases gradually. The influence of the wheel flat on TCF and AW is the most obvious, followed by TS and RCF.

2. RSFs have a significant influence on track deterioration.

There are two points worth mentioning here.

1. This study can be integrated into the bottomup-model based track charging model for estimating the damage and marginal cost of a vehicle on rail infrastructure. However, such a track charging model consists of two stages: (I) engineering simulation methods that estimate the track deterioration caused by vehicles; (II) econometric methods that estimate the relationship between the actual maintenance costs and the different deterioration mechanisms (Smith et al., 2017). Our work has limits because we investigated only the engineering simulation step.

2 . Since the actual wheel flat is usually $3 \mathrm{D}$, when the train is running on a curve, the wheel may be moved laterally, causing the contact length of the wheel flat and the actual length of the wheel flat to be different. When the train is running on a small-radius curve, it may even cause the WR contact to not occur in the flat. Therefore, this paper only analyzed the case of the train running on a straight line and did not analyze the case of the curve. Further investigation of running on the curve is needed.

The engineering applicability of this work requires further investigation and more comprehensive research, including more vehicle models and more rolling stock failures, should be continued. 


\section{Replication of results}

The unlisted data about the locomotive are confidential and the authors have no rights to provide it. However, the original simulated data are listed in Appendix B. Readers interested in the MATLAB code are encouraged to contact the corresponding author by e-mail.

\section{Contributors}

Yun-guang YE: conceptualization, formal analysis, funding acquisition, investigation, methodology, validation, visualization, writing-original draft, writing-review \& editing. Da-chuan SHI: conceptualization, formal analysis, investigation, methodology, writing-review \& editing. Sara POVEDA-REYES: formal analysis, funding acquisition, project administration, writing-review \& editing. Markus HECHT: funding acquisition, project administration, resources, software, and supervision.

\section{Conflict of interest}

Yun-guang YE, Da-chuan SHI, Sara POVEDA-REYES, and Markus HECHT declare that they have no conflict of interest.

\section{Open access}

This article is distributed under the terms of the Creative Commons Attribution 4.0 International License (http://creativecommons.org/licenses/by/4.0/), which permits use, duplication, adaptation, distribution and reproduction in any medium or format, as long as you give appropriate credit to the original author(s) and the source, provide a link to the Creative Commons license and indicate if changes were made.

\section{References}

Andreas S, Allan Z, Joseph P, et al., 2012. Development of the Future Rail Freight System to Reduce the Occurrences and Impact of Derailment. D-RAIL Project Report, European Commission.

Appel P, Hecht M, 2017. Möglichkeiten zur Lärmminderung des Schienengüterverkehrs in Deutschland. Lärmbekämpfung, 12(2):47-56 (in German).

Baeza L, Fayos J, Roda A, et al., 2008. High frequency railway vehicle-track dynamics through flexible rotating wheelsets. Vehicle System Dynamics, 46(7):647-659. https://doi.org/10.1080/00423110701656148

Belotti V, Crenna F, Michelini RC, et al., 2006. Wheel-flat diagnostic tool via wavelet transform. Mechanical Systems and Signal Processing, 20(8):1953-1966. https://doi.org/10.1016/j.ymssp.2005.12.012

Bernal E, Spiryagin M, Cole C, 2019. Wheel flat detectability for Y25 railway freight wagon using vehicle component acceleration signals. Vehicle System Dynamics, in press. https://doi.org/10.1080/00423114.2019.1657155
Bosso N, Gugliotta A, Zampieri N, 2018. Wheel flat detection algorithm for onboard diagnostic. Measurement, 123: 193-202. https://doi.org/10.1016/j.measurement.2018.03.072

Braghin F, Lewis R, Dwyer-Joyce RS, et al., 2006. A mathematical model to predict railway wheel profile evolution due to wear. Wear, 261(11-12):1253-1264. https://doi.org/10.1016/j.wear.2006.03.025

Bruni S, Alfi S, Gialleonardo ED, et al., 2016. Analysis of Passive and Mechatronic Steering Bogie Solutions for Freight Locomotives-Section 2.3 (DynafreightShift2Rail Poject). Report No. DYF-TSK2, 3-D-POL037-01, European Commission.

Burstow M, 2003. Whole Life Rail Model Application and Development for RSSB-Development of an RCF Damage Parameter. RSSB Report, AEATR-ES-2003-832 Issue 1, Rail Safety \& Standards Boards, London, UK.

Chaar N, Berg M, 2006. Simulation of vehicle-track interaction with flexible wheelsets, moving track models and field tests. Vehicle System Dynamics, 44(S1):921-931. https://doi.org/10.1080/00423110600907667

Chowdhury R, Adhikari S, 2012. Fuzzy parametric uncertainty analysis of linear dynamical systems: a surrogate modeling approach. Mechanical Systems and Signal Processing, 32:5-17. https://doi.org/10.1016/j.ymssp.2012.05.002

Chrismer S, Selig ET, 1993. Computer model for ballast maintenance planning. Proceedings of 5th International Heavy Haul Railway Conference, p.223-227.

Elkhoury N, Hitihamillage L, Moridpour S, et al., 2018. Degradation prediction of rail tracks: a review of the existing literature. The Open Transportation Journal, 12(1):88104. https://doi.org/10.2174/1874447801812010088

Enblom R, 2009. Deterioration mechanisms in the wheel-rail interface with focus on wear prediction: a literature review. Vehicle System Dynamics, 47(6):661-700. https://doi.org/10.1080/00423110802331559

Falomi S, Malvezzi M, Meli E, 2011. Multibody modeling of railway vehicles: innovative algorithms for the detection of wheel-rail contact points. Wear, 271(1-2):453-461. https://doi.org/10.1016/j.wear.2010.10.039

Halama R, Fajkoš R, Matušek P, et al., 2011. Contact defects initiation in railroad wheels-experience, experiments and modelling. Wear, 271(1-2):174-185. https://doi.org/10.1016/j.wear.2010.10.053

Han J, Zhong SQ, Xiao XB, et al., 2018. High-speed wheel/rail contact determining method with rotating flexible wheelset and validation under wheel polygon excitation. Vehicle System Dynamics, 56(8):1233-1249. https://doi.org/10.1080/00423114.2017.1408920

Hecht M, Leiste M, Jobstfinke D, et al., 2018. Roadmap zur Digitalisierung der Wagentechnischen Untersuchung. Technical Report, Technische Universität Berlin, 
Germany (in German).

Higgins C, Liu X, 2018. Modeling of track geometry degradation and decisions on safety and maintenance: a literature review and possible future research directions. Proceedings of the Institution of Mechanical Engineers, Part F: Journal of Rail and Rapid Transit, 232(5):13851397. https://doi.org/10.1177/0954409717721870

Liang B, Iwnicki SD, Zhao Y, et al., 2013. Railway wheel-flat and rail surface defect modelling and analysis by timefrequency techniques. Vehicle System Dynamics, 51(9): 1403-1421. https://doi.org/10.1080/00423114.2013.804192

Lyon D, 1972. The calculation of track forces due to dipped rail joints, wheel flats and rail welds. Proceedings of the 2nd ORE Colloquium on Technical Computer Programs.

Mitusch K, Hecht M, 2017. Lärm des Schienengüterverkehrswie weiter nach Einführung der Verbundbremssohle. ZEVrail, 141(8):294-300 (in German).

Öberg J, 2006. Track Deterioration of Ballasted Tracks: Marginal Cost Models for Different Railway Vehicles. TRITA-AVE Report No. 88, Division of Rail Vehicles, Royal Institute of Technology, Stockholm, Sweden.

Öberg J, Andersson E, 2009. Determining the deterioration cost for railway tracks. Proceedings of the Institution of Mechanical Engineers, Part F: Journal of Rail and Rapid Transit, 223(2):121-129. https://doi.org/10.1243/09544097jrrt222

Odolinski K, Nilsson JE, 2017. Estimating the marginal maintenance cost of rail infrastructure usage in Sweden; does more data make a difference? Economics of Transportation, 10:8-17. https://doi.org/10.1016/j.ecotra.2017.05.001

Pearce TG, Sherratt ND, 1991. Prediction of wheel profile wear. Wear, 144(1-2):343-351. https://doi.org/10.1016/0043-1648(91)90025-p

Peng B, Iwnicki S, Shackleton P, et al., 2019. Comparison of wear models for simulation of railway wheel polygonization. Wear, 436-437:203010. https://doi.org/10.1016/j.wear.2019.203010

Pombo J, Ambrósio J, Pereira M, et al., 2011. Development of a wear prediction tool for steel railway wheels using three alternative wear functions. Wear, 271(1-2):238-245. https://doi.org/10.1016/j.wear.2010.10.072

Regazzi D, Alfi S, Bruni S, et al., 2019. Cost-driven and eliability-driven analysis of wagon condition data (INNOWAG Project). European Commission. https://cordis.europa.eu/project/rcn/206229/factsheet/en

Shenton MJ, 1984. Ballast deformation and track deterioration. Proceedings of a Conference on Track Technology, p.253-265.

Smith A, Iwnicki S, Kaushal A, et al., 2017. Estimating the relative cost of track damage mechanisms: combining economic and engineering approaches. Proceedings of the Institution of Mechanical Engineers, Part F: Journal of Rail and Rapid Transit, 231(5):620-636. https://doi.org/10.1177/0954409717698850

Smith ASJ, Kaushal A, Odolinski K, et al., 2015. Estimating the damage and marginal cost of different vehicle types on rail infrastructure: combining economic and engineering approaches. The Stephenson Conference: Research for Railways, p.21-23.

Smith ASJ, Odolinski K, Saeed HN, et al., 2016. Estimating the Marginal Cost of Different Vehicle Types on Rail Infrastructure. Working Papers in Transport Economics, KTH Royal Institute of Technology, Sweden. https://ideas.repec.org/p/hhs/ctswps/2016_026.html

Smith RA, 2003. The wheel-rail interface-some recent accidents. Fatigue \& Fracture of Engineering Materials \& Structures, 26(10):901-907. https://doi.org/10.1046/j.1460-2695.2003.00701.x

Soleimanmeigouni I, Ahmadi A, Kumar U, 2018. Track geometry degradation and maintenance modelling: a review. Proceedings of the Institution of Mechanical Engineers, Part F: Journal of Rail and Rapid Transit, 232(1):73-102. https://doi.org/10.1177/0954409716657849

Tao GQ, Du X, Zhang HJ, et al., 2017. Development and validation of a model for predicting wheel wear in high-speed trains. Journal of Zhejiang UniversitySCIENCE A (Applied Physics \& Engineering), 18(8): 603-616. https://doi.org/10.1631/jzus.a1600693

Tao GQ, Ren DX, Wang LF, et al., 2018. Online prediction model for wheel wear considering track flexibility. Multibody System Dynamics, 44(3):313-334. https://doi.org/10.1007/s11044-018-09633-5

Wheat P, Smith ASJ, 2008. Assessing the marginal infrastructure maintenance wear and tear costs for Britain's railway network. Journal of Transport Economics and Policy (JTEP), 42(2):189-224.

Wu XW, Rakheja S, Ahmed AKW, et al., 2018. Influence of a flexible wheelset on the dynamic responses of a high-speed railway car due to a wheel flat. Proceedings of the Institution of Mechanical Engineers, Part F: Journal of Rail and Rapid Transit, 232(4):1033-1048. https://doi.org/10.1177/0954409717708895

Xin CF, Lu Q, Ai CF, et al., 2017. Optimization of hard modified asphalt formula for gussasphalt based on uniform experimental design. Construction and Building Materials, 136:556-564. https://doi.org/10.1016/j.conbuildmat.2017.01.068

Ye YG, Sun Y, 2020. Reducing wheel wear from the perspective of rail track layout optimization. Proceedings of the Institution of Mechanical Engineers, Part K: Journal of Multi-body Dynamics, in press. https://doi.org/10.1177/1464419320956831

Ye YG, Shi DC, Krause P, et al., 2020a. A data-driven method for estimating wheel flat length. Vehicle System Dynamics, 
58(9):1329-1347.

https://doi.org/10.1080/00423114.2019.1620956

Ye YG, Sun Y, Dongfang SP, et al., 2020b. Optimizing wheel profiles and suspensions for railway vehicles operating on specific lines to reduce wheel wear: a case study. Multibody System Dynamics, in press. https://doi.org/10.1007/s11044-020-09722-4

Ye YG, Shi DC, Sun Y, et al., 2020c. Rotary-scaling finetuning (RSFT) method for optimizing railway wheel profiles and its application to a locomotive. Railway Engineering Science, 28(2):160-183.

Ye YG, Shi DC, Krause P, et al., 2020d. Wheel flat can cause or exacerbate wheel polygonization. Vehicle System Dynamics, 58(10):1575-1604. https://doi.org/10.1080/00423114.2019.1636098

Zobory I, 1997. Prediction of wheel/rail profile wear. Vehicle System Dynamics, 28(2-3):221-259. https://doi.org/10.1080/00423119708969355

\section{中文概要}

题 目: 量化铁路车辆机械故障对轨道退化的影响

目 的: 了解和量化铁路车辆机械故障对铁路基础设施退 化的影响有利于提高列车安全性, 合理制定维护 策略, 以及优化轨道收费模型。本研究为欧洲 Shift2Rail-Assets4rail 项目的一部分（报告以非公 开的形式被递交), 旨在量化铁路车辆机械故障 对轨道退化的影响, 为调整现有的轨道收费模型 提供合理的建议。

创新点：1. 分析一个常见的铁路车辆机械故障（擦伤）对 四个用于轨道收费模型的量化指标的影响；2. 引 入金代理模型方法以减少仿真次数。

方 法: 1. 建立一个带有擦伤的机车多体动力学模型, 并 考虑车轮和轨道的柔性; 2. 引入金代理模型以量 化车辆速度和擦伤尺寸对四种损坏机制（轨道沉 降、轨道构件疲劳、钢轨磨耗和钢轨滚动接触疲 劳）的影响。

结 论: 1. 轨道沉降、轨道构件疲劳和钢轨磨耗随着擦伤 尺寸和车速的增加而急剧增加, 并且这种增加趋 势随着擦伤尺寸和车速的增加而变得更加尖锐。 2. 在低速时, 滚动接触疲劳随着擦伤尺寸的增加 而逐渐增加; 在高速时, 它首先急剧增加, 然后 逐渐减小。3. 擦伤对轨道构件疲劳和钢轨磨耗的 影响最为显著, 其次是轨道沉降和滚动接触 疲劳。

关键词: 铁路车辆故障; 轨道退化; 量化; 轨道收费; 擦伤

\section{Appendix A}

Table A1 Primary parameters of the locomotive/ track model

\begin{tabular}{|c|c|}
\hline Parameter & Value \\
\hline Vehicle frame mass $(\mathrm{kg})$ & 61882 \\
\hline Bogie frame mass $(\mathrm{kg})$ & 4698.5 \\
\hline Wheelset mass (including axlebox) (kg) & 3562 \\
\hline Motor mass (kg) & 3068 \\
\hline Sleeper mass (kg) & 330 \\
\hline $\begin{array}{l}\text { Carbody roll moment of inertia } \\
\left(\mathrm{kg} \cdot \mathrm{m}^{2}\right)\end{array}$ & 95970 \\
\hline $\begin{array}{l}\text { Carbody pitch moment of inertia } \\
\left(\mathrm{kg} \cdot \mathrm{m}^{2}\right)\end{array}$ & 1539990 \\
\hline $\begin{array}{l}\text { Carbody yaw moment of inertia } \\
\left(\mathrm{kg} \cdot \mathrm{m}^{2}\right)\end{array}$ & 1536740 \\
\hline $\begin{array}{l}\text { Bogie frame roll moment of } \\
\text { inertia }\left(\mathrm{kg} \cdot \mathrm{m}^{2}\right)\end{array}$ & 2260 \\
\hline $\begin{array}{l}\text { Bogie frame pitch moment of } \\
\text { inertia }\left(\mathrm{kg} \cdot \mathrm{m}^{2}\right)\end{array}$ & 8480 \\
\hline $\begin{array}{l}\text { Bogie frame yaw moment of } \\
\text { inertia }\left(\mathrm{kg} \cdot \mathrm{m}^{2}\right)\end{array}$ & 10360 \\
\hline $\begin{array}{l}\text { Wheelset roll moment of inertia } \\
\left(\mathrm{kg} \cdot \mathrm{m}^{2}\right)\end{array}$ & 2064 \\
\hline $\begin{array}{l}\text { Wheelset pitch moment of inertia } \\
\left(\mathrm{kg} \cdot \mathrm{m}^{2}\right)\end{array}$ & 573 \\
\hline Wheelset yaw moment of inertia $\left(\mathrm{kg} \cdot \mathrm{m}^{2}\right)$ & 2064 \\
\hline Motor roll moment of inertia $\left(\mathrm{kg} \cdot \mathrm{m}^{2}\right)$ & 320 \\
\hline Motor pitch moment of inertia $\left(\mathrm{kg} \cdot \mathrm{m}^{2}\right)$ & 350 \\
\hline Motor yaw moment of inertia $\left(\mathrm{kg} \cdot \mathrm{m}^{2}\right)$ & 320 \\
\hline Distance between center pivots (m) & 8.9 \\
\hline Wheel base (m) & 2.8 \\
\hline Wheel rolling circle diameter $(\mathrm{mm})$ & 1250 \\
\hline Gauge distance (mm) & 1435 \\
\hline $\begin{array}{l}\text { Primary suspension stiffness } \\
\text { (each axlebox) }(\mathrm{kN} / \mathrm{m})\end{array}$ & $\begin{array}{c}36000,4830 \\
2910\end{array}$ \\
\hline $\begin{array}{l}\text { Secondary suspension stiffness } \\
\text { (each spring) }(\mathrm{kN} / \mathrm{m})\end{array}$ & $\begin{array}{l}2265,2265 \\
5570\end{array}$ \\
\hline Contact stiffness, $k_{\mathrm{c}}(\mathrm{kN} / \mathrm{m})$ & Non-linear \\
\hline Fastener stiffness, $k_{\mathrm{fy}}, k_{\mathrm{fz}}(\mathrm{kN} / \mathrm{m})$ & 1700,280000 \\
\hline Ballast stiffness, $k_{\mathrm{b} y}, k_{\mathrm{b} z}(\mathrm{kN} / \mathrm{m})$ & 20000,75000 \\
\hline Contact damping, $c_{\mathrm{c}}(\mathrm{kN} \cdot \mathrm{s} / \mathrm{m})$ & 10 \\
\hline Fastener damping, $c_{\mathrm{fy}}, c_{\mathrm{fz}}(\mathrm{kN} \cdot \mathrm{s} / \mathrm{m})$ & $5.5,63$ \\
\hline Ballast damping, $c_{\mathrm{by} y}, c_{\mathrm{b} z}(\mathrm{kN} \cdot \mathrm{s} / \mathrm{m})$ & 49,94 \\
\hline $\begin{array}{l}\text { Friction coefficient between } \\
\text { wheels and rails }\end{array}$ & 0.35 \\
\hline Poisson's ratio & 0.28 \\
\hline Wheel profile & S1002 \\
\hline Rail profile & UIC60e2 \\
\hline Wheel-rail contact algorithm & $\begin{array}{c}\text { Hertzian contact }+ \\
\text { FASTSIM }\end{array}$ \\
\hline
\end{tabular}




\section{Appendix B}

Table B1 Simulated results concerning $Q, T_{\mathrm{s}}, T_{\mathrm{cf}}, T \gamma$, and $\boldsymbol{R}_{\mathrm{cf}}$

\begin{tabular}{|c|c|c|c|c|c|c|c|c|c|}
\hline \multirow{2}{*}{$\begin{array}{c}\text { Velocity } \\
(\mathrm{km} / \mathrm{h})\end{array}$} & \multicolumn{9}{|c|}{$Q(\mathrm{kN})$} \\
\hline & $L_{\mathrm{f}}=0 \mathrm{~mm}$ & $L_{\mathrm{f}}=5 \mathrm{~mm}$ & $L_{\mathrm{f}}=10 \mathrm{~mm}$ & $L_{\mathrm{f}}=15 \mathrm{~mm}$ & $L_{\mathrm{f}}=20 \mathrm{~mm}$ & $L_{\mathrm{f}}=25 \mathrm{~mm}$ & $L_{\mathrm{f}}=30 \mathrm{~mm}$ & $L_{\mathrm{f}}=35 \mathrm{~mm}$ & $L_{\mathrm{f}}=40 \mathrm{~mm}$ \\
\hline 30 & 138.772 & 204.644 & 364.763 & 543.094 & 745.865 & 905.407 & 1054.545 & 1211.643 & 1354.305 \\
\hline 40 & 147.408 & 228.927 & 409.859 & 621.881 & 859.481 & 1064.443 & 1291.836 & 1524.398 & 1755.420 \\
\hline 50 & 157.675 & 249.777 & 437.228 & 663.460 & 935.775 & 1164.950 & 1420.208 & 1691.860 & 1953.971 \\
\hline 60 & 166.295 & 263.598 & 485.110 & 726.141 & 1019.990 & 1263.348 & 1543.853 & 1819.356 & 2096.783 \\
\hline 70 & 176.524 & 283.405 & 543.348 & 796.832 & 1116.920 & 1369.828 & 1657.456 & 1963.951 & 2284.305 \\
\hline 80 & 184.785 & 309.817 & 566.773 & 836.709 & 1171.126 & 1451.327 & 1767.410 & 2101.838 & 2417.527 \\
\hline 90 & 217.001 & 315.049 & 591.014 & 867.626 & 1226.383 & 1518.982 & 1850.138 & 2209.940 & 2573.360 \\
\hline \multirow{2}{*}{$\begin{array}{l}\text { Velocity } \\
(\mathrm{km} / \mathrm{h})\end{array}$} & \multicolumn{9}{|c|}{$\overline{T T_{\mathrm{s}}}$} \\
\hline & $L_{\mathrm{f}}=0 \mathrm{~mm}$ & $L_{\mathrm{f}}=5 \mathrm{~mm}$ & $L_{\mathrm{f}}=10 \mathrm{~mm}$ & $L_{\mathrm{f}}=15 \mathrm{~mm}$ & $L_{\mathrm{f}}=20 \mathrm{~mm}$ & $L_{\mathrm{f}}=25 \mathrm{~mm}$ & $L_{\mathrm{f}}=30 \mathrm{~mm}$ & $L_{\mathrm{f}}=35 \mathrm{~mm}$ & $L_{\mathrm{f}}=40 \mathrm{~mm}$ \\
\hline 30 & 2312281 & 3699699 & 7445412 & 12051863 & 17691918 & 22368506 & 26900741 & 31822841 & 36410982 \\
\hline 40 & 2487516 & 4237303 & 8573204 & 14198479 & 21003025 & 27206566 & 34388771 & 42015022 & 49837530 \\
\hline 50 & 2698661 & 4708626 & 9270690 & 15355061 & 23279469 & 30345009 & 38565720 & 47662454 & 56737024 \\
\hline 60 & 2878188 & 5025690 & 10512903 & 17127384 & - 25838098 & 33473291 & 42664706 & 52042248 & 61792427 \\
\hline 70 & 3093769 & 5486168 & 12058706 & 19165037 & 28837802 & 36916582 & 46492242 & 57087854 & 68540600 \\
\hline 80 & 3269807 & 6110741 & 12690557 & 20331556 & 30539796 & 39590530 & 50249714 & 61972728 & 73406530 \\
\hline 90 & 3971679 & 6235827 & 13350234 & - 21244100 & 32291870 & 41834445 & 53109540 & 009 & 79170086 \\
\hline \multirow{2}{*}{$\begin{array}{l}\text { Velocity } \\
(\mathrm{km} / \mathrm{h})\end{array}$} & \multicolumn{9}{|c|}{ 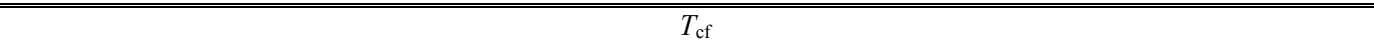 } \\
\hline & $L_{\mathrm{f}}=0 \mathrm{~mm}$ & $L_{\mathrm{f}}=5 \mathrm{~mm}$ & $L_{\mathrm{f}}=10 \mathrm{~mm}$ & $L_{\mathrm{f}}=15 \mathrm{~mm}$ & $L_{\mathrm{f}}=20 \mathrm{~mm}$ & $L_{\mathrm{f}}=25 \mathrm{~mm}$ & $L_{\mathrm{f}}=30 \mathrm{~mm}$ & $L_{\mathrm{f}}=35 \mathrm{~mm}$ & $L_{\mathrm{f}}=40 \mathrm{~mm}$ \\
\hline 30 & $7.550 \times 10^{16}$ & $9.326 \times 10^{16}$ & $1.759 \times 10^{17}$ & $3.581 \times 10^{17}$ & $7.227 \times 10^{17}$ & $1.158 \times 10^{18}$ & $1.708 \times 10^{18}$ & $2.458 \times 10^{18}$ & $3.310 \times 10^{18}$ \\
\hline 40 & $8.113 \times 10^{16}$ & $1.021 \times 10^{17}$ & $2.103 \times 10^{17}$ & $4.731 \times 10^{17}$ & $1.009 \times 10^{18}$ & $1.736 \times 10^{18}$ & $2.896 \times 10^{18}$ & $4.537 \times 10^{18}$ & $6.696 \times 10^{18}$ \\
\hline 50 & $8.664 \times 10^{16}$ & $1.159 \times 10^{17}$ & $2.390 \times 10^{17}$ & $5.478 \times 10^{17}$ & $1.245 \times 10^{18}$ & $2.191 \times 10^{18}$ & $3.726 \times 10^{18}$ & $6.023 \times 10^{18}$ & $8.999 \times 10^{18}$ \\
\hline 60 & $9.383 \times 10^{16}$ & $1.268 \times 10^{17}$ & $2.919 \times 10^{17}$ & $6.761 \times 10^{17}$ & $1.551 \times 10^{18}$ & $2.717 \times 10^{18}$ & $4.676 \times 10^{18}$ & $7.364 \times 10^{18}$ & $1.096 \times 10^{19}$ \\
\hline 70 & $1.044 \times 10^{17}$ & $1.440 \times 10^{17}$ & $3.704 \times 10^{17}$ & $8.494 \times 10^{17}$ & $1.971 \times 10^{18}$ & $3.386 \times 10^{18}$ & $5.695 \times 10^{18}$ & $9.130 \times 10^{18}$ & $1.397 \times 10^{19}$ \\
\hline 80 & $1.225 \times 10^{17}$ & $1.759 \times 10^{17}$ & $4.275 \times 10^{17}$ & $9.901 \times 10^{17}$ & $2.285 \times 10^{18}$ & $4.032 \times 10^{18}$ & $6.902 \times 10^{18}$ & $1.118 \times 10^{19}$ & $1.658 \times 10^{19}$ \\
\hline 90 & $1.557 \times 10^{17}$ & $2.002 \times 10^{17}$ & $4.791 \times 10^{17}$ & $1.085 \times 10^{18}$ & $2.567 \times 10^{18}$ & $4.534 \times 10^{18}$ & $7.785 \times 10^{18}$ & $1.279 \times 10^{19}$ & $1.969 \times 10^{19}$ \\
\hline \multirow{2}{*}{$\begin{array}{l}\text { Velocity } \\
(\mathrm{km} / \mathrm{h})\end{array}$} & \multicolumn{9}{|c|}{$T \gamma(\mathrm{N}$ or $\mathrm{J} / \mathrm{m})$} \\
\hline & $L_{\mathrm{f}}=0 \mathrm{~mm}$ & $L_{\mathrm{f}}=5 \mathrm{~mm}$ & $L_{\mathrm{f}}=10 \mathrm{~mm}$ & $L_{\mathrm{f}}=15 \mathrm{~mm}$ & $L_{\mathrm{f}}=20 \mathrm{~mm}$ & $L_{\mathrm{f}}=25 \mathrm{~mm}$ & $L_{\mathrm{f}}=30 \mathrm{~mm}$ & $L_{\mathrm{f}}=35 \mathrm{~mm}$ & $L_{\mathrm{f}}=40 \mathrm{~mm}$ \\
\hline 30 & 8.000 & 13.081 & 33.409 & 86.876 & 166.700 & 255.295 & 353.385 & 472.513 & 599.063 \\
\hline 40 & 10.223 & 16.563 & 44.613 & 111.808 & 208.900 & 312.986 & 451.807 & 632.564 & 805.492 \\
\hline 50 & 12.565 & 21.548 & 59.440 & 133.973 & 257.471 & 388.604 & 558.205 & 762.245 & 1015.930 \\
\hline 60 & 15.998 & 28.597 & 81.567 & 173.495 & 325.282 & 476.062 & 718.515 & 1018.48 & 1437.830 \\
\hline 70 & 19.264 & 35.711 & 106.310 & 218.346 & 404.299 & 644.176 & 1018.350 & 1492.250 & 2168.330 \\
\hline 80 & 20.723 & 41.936 & 127.814 & 268.715 & 543.879 & 899.166 & 1415.950 & 2065.450 & 2799.730 \\
\hline 90 & 21.029 & 49.129 & 159.960 & 332.594 & 707.707 & 1178.000 & 1891.720 & 2513.870 & 3272.990 \\
\hline \multirow{2}{*}{$\begin{array}{l}\text { Velocity } \\
(\mathrm{km} / \mathrm{h})\end{array}$} & \multicolumn{9}{|c|}{$R_{\mathrm{cf}}\left(\times 10^{-5} /\right.$ axle $)$} \\
\hline & $L_{\mathrm{f}}=0 \mathrm{~mm}$ & $L_{\mathrm{f}}=5 \mathrm{~mm}$ & $L_{\mathrm{f}}=10 \mathrm{~mm}$ & $L_{\mathrm{f}}=15 \mathrm{~mm}$ & $L_{\mathrm{f}}=20 \mathrm{~mm}$ & $L_{\mathrm{f}}=25 \mathrm{~mm}$ & $L_{\mathrm{f}}=30 \mathrm{~mm}$ & $L_{\mathrm{f}}=35 \mathrm{~mm}$ & $L_{\mathrm{f}}=40 \mathrm{~mm}$ \\
\hline 30 & 0 & 0 & 0.092 & 0.537 & 0.991 & 1.371 & 1.889 & 2.228 & 2.342 \\
\hline 40 & 0 & 0 & 0.151 & 0.684 & 1.061 & 1.670 & 2.219 & 2.786 & 3.112 \\
\hline 50 & 0 & 0 & 0.219 & 0.739 & 1.249 & 2.022 & 2.740 & 3.307 & 3.685 \\
\hline 60 & 0 & 0 & 0.324 & 1.029 & 1.720 & 2.388 & 3.512 & 4.504 & 4.764 \\
\hline 70 & 0 & 0 & 0.409 & 1.333 & 2.050 & 3.712 & 5.638 & 6.302 & 6.714 \\
\hline 80 & 0 & 0 & 0.521 & 1.647 & 3.017 & 5.833 & 8.048 & 8.778 & 8.507 \\
\hline 90 & 0 & 0 & 0.765 & 1.993 & 4.581 & 7.843 & 9.623 & 10.172 & 9.561 \\
\hline
\end{tabular}

